\title{
Direct Polycondensation Reaction Using Polymeric Triphenylphosphine as an Initiator
}

\author{
Naoya OGATA, Kohei SAnui, Masayoshi Watanabe, \\ and Hideko SAKAI \\ Department of Chemistry, Sophia University, \\ 7-1 Kioi-cho, Chiyoda-ku, Tokyo 102, Japan
}

(Received June 24, 1987)

\begin{abstract}
Triphenylphosphine which is known as an effective initiator for direct polycondensation, was immobilized into polymers by polymerizing and copolymerizing with diphenylstyrylphosphine. Copolymerization behavior of diphenylstyrylphosphine with 4-vinylpyridine was analyzed. Polymeric triphenylphosphine could initiate the direct polycondensation to form either polyamide or polyester and a recycling system for the regeneration of triphenylphosphine moiety was proposed.
\end{abstract}

KEY WORDS Direct polycondensation / Triphenylphosphine / Diphenylstyrylphosphine / Polyamide / Polyester /

Direct polycondensation reactions have been recently developed by using various initiators under mild conditions for synthesis of polyamides or polyesters. Among various initiators, triphenylphosphite ${ }^{1}$ and triphenylphosphine $^{2}$ are effective initiators to initiate direct polycondensation under mild conditions.

One of the problems of direct polycondensation is that a stoichiometric amount of initiators to monomers is required to initiate polycondensation reactions, and a recycling system of the initiators has to be established for practical application of direct polycondensation.

Triphenylphosphine which is used for the direct polycondensation reaction, is transformed into triphenylphosphine oxide after reacting with carboxylic acid, and regeneration of the initiator requires the reduction of triphenylphosphine oxide to triphenylphosphine, which is usually difficult. An easy recycling system of the initiator is proposed for the direct polycondensation method by using triphenylphosphine dichloride ${ }^{3}$ which was easily obtained by the reaction of triphenylphosphine oxide with oxalyl chloride. Triphenylphosphine dichloride which is pentavalent, was found to be effective for the synthesis of either polyamides or polyesters having high molecular weights and a recycling system was established as shown below:

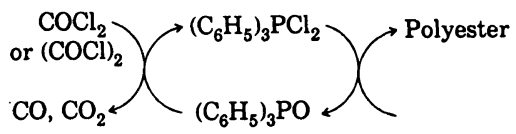

The recovery and regeneration of the triphenylphosphine moiety becomes much easier when the triphenylphosphine moiety is immobilized into a polymer. Moreover, the direct polycondensation reaction requires the coexistence of pyridine as an acid acceptor. When both triphenylphosphine and pyridine moieties are immobilized into a polymer, it is expected that the direct polycondensation reaction can be carried out as a semi-continuous process, as illustrated in Figure 1.

This paper deals with the direct polyconden- 


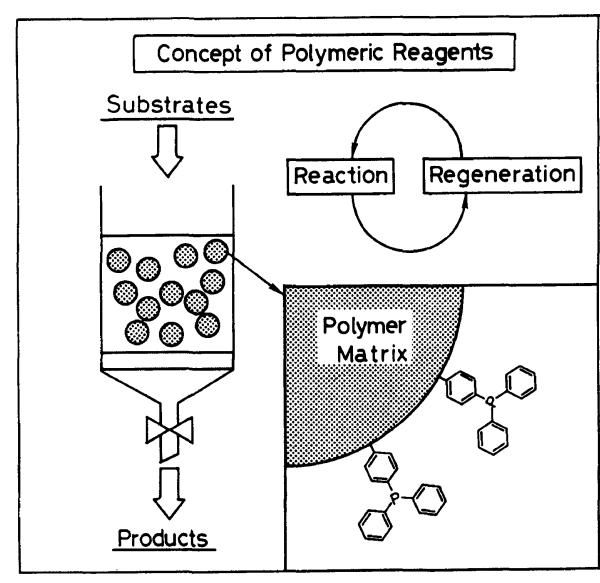

Figure 1. Recycling system of polymeric TTP for direct polycondensation reactions.

sation method using polymeric triphenylphosphine as an initiator for the synthesis of polyamide or polyester with intention to approach to a semi-continuous process of direct polycondensation.

\section{EXPERIMENTAL}

\section{Synthesis of 4-Styryldiphenylphosphine (4-} $S D P$ )

4-SDP was synthesized by the method of Relles and Schluenz ${ }^{4}: 14.6 \mathrm{~g}$ of powdered magnesium were reacted with $3 \mathrm{~cm}^{3}$ of ethyl bromide in $10 \mathrm{~cm}^{3}$ of tetrahydrofuran (THF) under nitrogen atmosphere and then, $41.4 \mathrm{~g}$ of 4 chlorostyrene in $75 \mathrm{~cm}^{3}$ of THF was added into the solution in a period of $1 \mathrm{~h}$, keeping temperatures in the range of $45-50^{\circ} \mathrm{C}$. The reacted solution was diluted by $50 \mathrm{~cm}^{3}$ of THF, which was added to a mixture of $55.6 \mathrm{~g}$ of chlorodiphenylphosphine and $200 \mathrm{~cm}^{3}$ of THF within $1 \mathrm{~h}$, keeping temperature at 5$10^{\circ} \mathrm{C}$.

The reacted solution was poured into $300 \mathrm{~cm}^{3}$ water containing $49.5 \mathrm{~g}$ of ammonium chloride and the THF layer was separated. The THF solution was dried over anhydrous sodium sulfate in the presence of $0.37 \mathrm{~g}$ of $t$-butyl catechol and then it was concentrated to about
$200 \mathrm{~cm}^{3}$, followed by pouring into $700 \mathrm{~cm}^{3}$ of $n$-hexane. A precipitated polymer was filtered off and the filtrate was concentrated by removing THF and $n$-hexane. The residual oily product was recrystallized from ethanol. Yield $22.8 \mathrm{~g}(32 \%), \mathrm{mp} 76-78^{\circ} \mathrm{C}$ (lit. ${ }^{4} \mathrm{mp} 77-$ $78^{\circ} \mathrm{C}$ ). C, $82.86 \%$ (calcd $83.32 \%$ ); H, $5.96 \%$ (calcd $5.94 \%$ ).

\section{Polymerization and Copolymerization}

4-SDP was polymerized in benzene and also copolymerized with 4-vinylpyridine (4VPy) at various molar ratios in $N, N$ dimethylformamide (DMF) at $60^{\circ} \mathrm{C}$ in the presence of AIBN as a radical initiator. Poly(4-SDP) and poly(4-SDP-co-4-VPy)s were recovered by pouring into methanol or ether, respectively.

Poly(4-SDP) was oxidized in methylene chloride in the presence of peracetic acid. Hereafter, the homopolymer from 4-SDP is called Poly-1 and copolymers from 4-SDP and 4-VPy, Poly(1-co-2). Synthetic routes are schematically shown in Figure 2.

\section{Direct Polycondensation \\ (1) Model Reaction}

Each portion of $0.72 \mathrm{~g}(0.0025 \mathrm{~mol}$ of repeating units) of Poly- $1,0.20 \mathrm{~g}(0.0021 \mathrm{~mol})$ of aniline and $0.26 \mathrm{~g}(0.0021 \mathrm{~mol})$ of benzoic acid was dissolved in $5 \mathrm{~cm}^{3}$ of pyridine and then, $0.71 \mathrm{~g}(0.003 \mathrm{~mol})$ of hexachloroethane $\left(\mathrm{C}_{2} \mathrm{Cl}_{6}\right)$ was added to the solution. The solution was stirred at room temperature for $30 \mathrm{~min}$ and the resulting product was recovered by pouring the solution into water. The product was recrystallized from benzene, which was identified as benzanilide from elemental and infrared analyses. mp $163-165^{\circ} \mathrm{C}$ (lit. ${ }^{5} \mathrm{mp} 163^{\circ} \mathrm{C}$ ). Yield: $91 \%$.

(2) Poly-1 Oxide and $(\mathrm{COCl})_{2}$ (System (1))

A portion of $9.75 \mathrm{~g}$ of Poly-1 oxide $(0.032$ mol of repeating units) was dissolved in $20 \mathrm{~cm}^{3}$ of solvent such as monochlorobenzene, followed by the addition of $4.10 \mathrm{~g}(0.032 \mathrm{~mol})$ of oxalyl chloride in $10 \mathrm{~cm}^{3}$ of solvents. After 


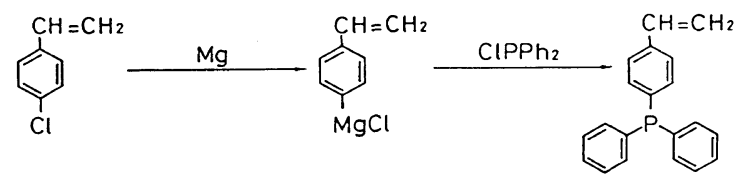

1
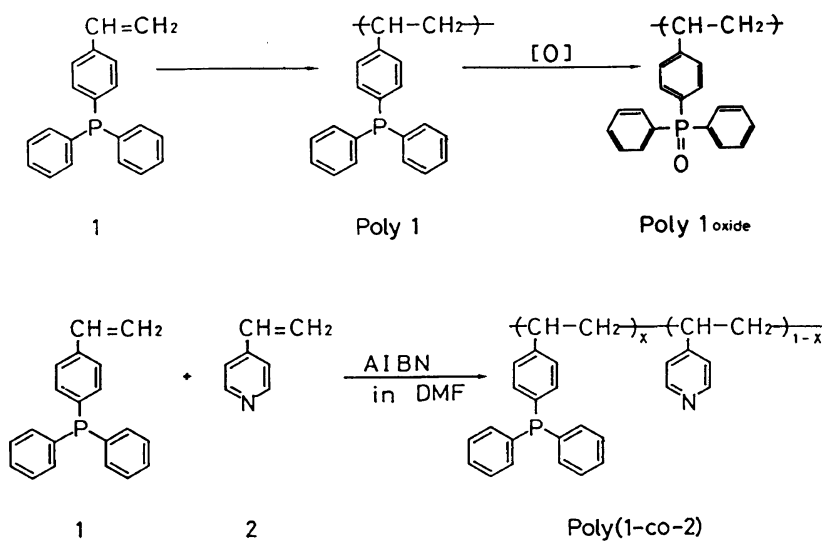

Figure 2. Synthetic routes of monomer 1 and poly 1 or poly(1-co-2).

evolution of the gas, $0.015 \mathrm{~mol}$ of dicarboxylic acids or $0.03 \mathrm{~mol}$ of 4 -aminobenzoic acid (4ABA) was added, followed by heating at refluxing temperature of the solvents for $5 \mathrm{~min}$. After cooling the solution, $0.015 \mathrm{~mol}$ of diol or diamine was added to carry out the direct polycondensation except in the case of 4-ABA. To the solution was added $0.06 \mathrm{~mol}$ of pyridine or triethylamine as an acid acceptor. The entire solution was heated under reflux for $4 \mathrm{~h}$. Polymers were recovered by pouring the solution into $100 \mathrm{~cm}^{3}$ of methanol so as to precipitate either polyamide or polyester. The precipitated polymers were treated for $24 \mathrm{~h}$ in a Soxleht apparatus with refluxing methanol, followed by water so that the polymeric initiators were eliminated from the resulting polymers.

(3) Poly-1 or Poly(1-co-2) and $\mathrm{C}_{2} \mathrm{Cl}_{6}$ (System (2))

Poly-1 or poly(1-co-2) and monomers were dissolved in a solvent as in the case of the system (1) and then $\mathrm{C}_{2} \mathrm{Cl}_{6}$ was added to the solution at a molar ratio of $1.0,1.2$, and 1.5 to the monomer, respectively. The procedure for the direct polycondensation was the same as the system (1).

\section{RESULTS AND DISCUSSION}

\section{Synthesis of Polymeric Triphenylphosphine (TPP)}

4-SDP was polymerized and copolymerized with 4-VPy and the structures of polymers were identified by NMR spectra as shown in Figures 3 and 4 . The results of the copolymerization are summarized in Table I. Monomer reactivity ratios of the copolymerization were calculated by the Kelen-Tüdôs $\operatorname{method}^{6}$ as $r_{1}=0.729$ and $r_{2}=0.716$, which were obtained from the copolymer composition curve as shown in Figure 5. The $Q-e$ values of 4-SDP were calculated as $Q=1.35$ and $e=-1.01$ when the $Q-e$ values of $4-\mathrm{VPy}$ were used as $Q=0.82$ and $e=-0.20$. From these results, the copolymers were estimated to have a random tendency of sequence distribution as $r_{1} r_{2}<1.0$. 

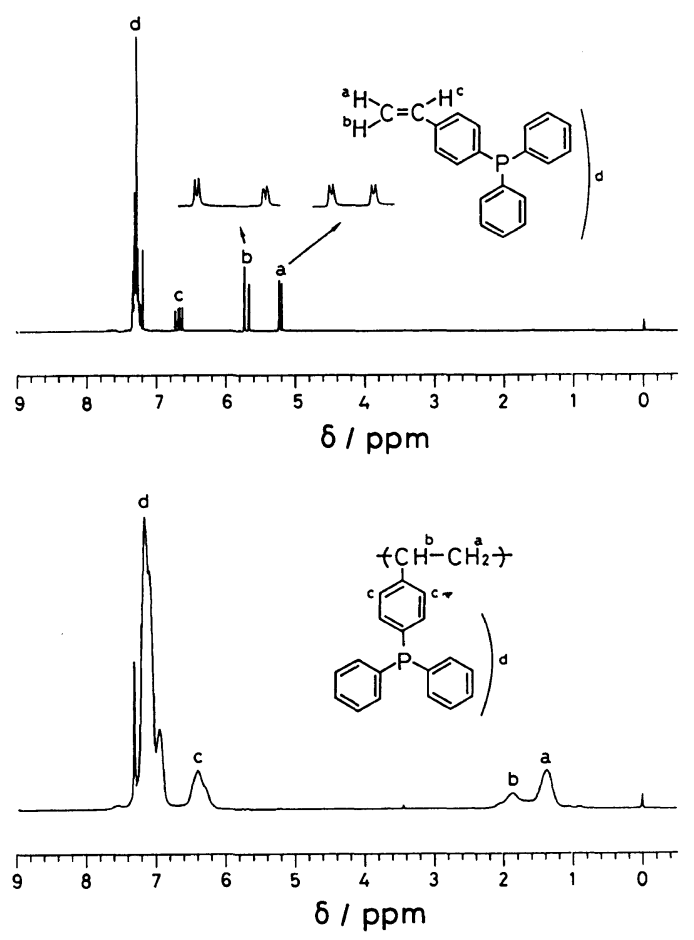

Figure 3. ${ }^{1} \mathrm{H}$ NMR spectra of 1 and poly-1.

Table I. Copolymerization of 4-SDP and 4-VPy

\begin{tabular}{|c|c|c|c|}
\hline \multirow{3}{*}{$\frac{4-\mathrm{SDP} \text { in feed }}{\mathrm{mol}^{\mathrm{o}} \mathrm{r}}$} & \multicolumn{3}{|c|}{ Copolymers } \\
\hline & \multirow{2}{*}{$\frac{\text { Yield }}{\%}$} & \multirow{2}{*}{$\frac{4-\mathrm{SDP}}{\mathrm{mol} \%}$} & \multirow{2}{*}{$\eta_{\mathrm{sp}} / c^{\mathrm{a}}$} \\
\hline & & & \\
\hline 100 & 91 & 100 & 0.21 \\
\hline 90 & 26 & 87 & 0.26 \\
\hline 80 & 21 & 77 & 0.23 \\
\hline 60 & 19 & 61 & 0.20 \\
\hline 40 & 4 & 41 & 0.27 \\
\hline 20 & 21 & 21 & 0.31 \\
\hline 10 & 24 & 14 & 0.26 \\
\hline
\end{tabular}

a Measured at a concentration of $0.1 \mathrm{~g} / 10 \mathrm{~cm}^{3}$ in DMF at $30^{\circ} \mathrm{C}$.

\section{Direct Polycondensation}

(1) Synthesis of Polyamide

The synthesis of polyamide was carried out by using both initiators of the systems (1) and (2) and results are summarized in Table II. It is seen that these polymeric TPP could initiate

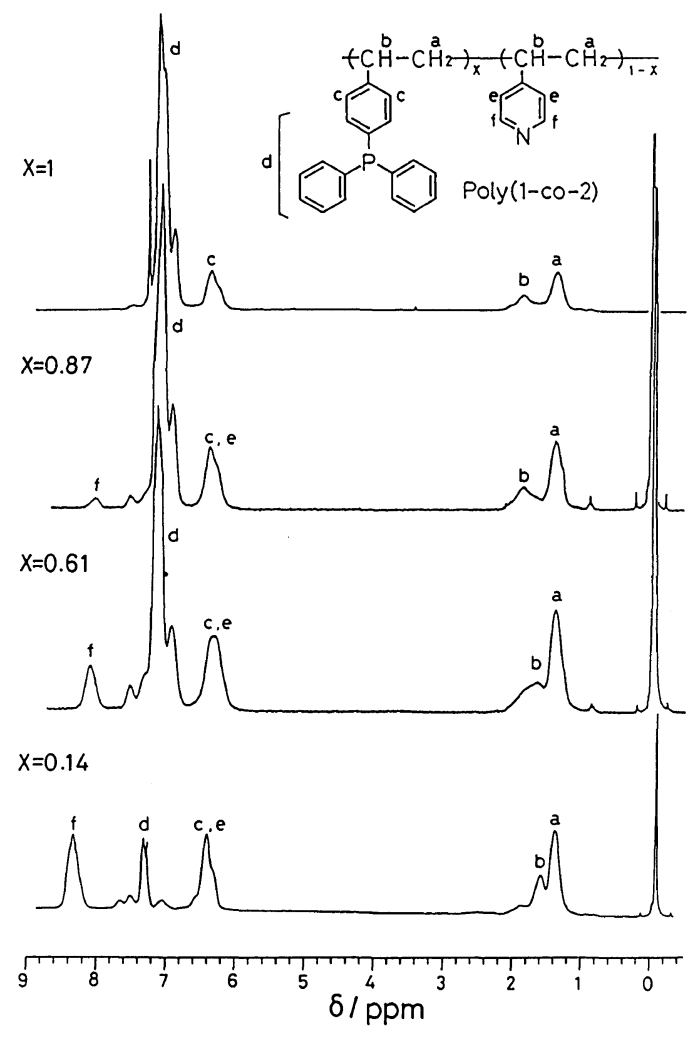

Figure 4. ${ }^{1} \mathrm{H}$ NMR spectra of poly $(1-c o-2)$ of various molar ratios of $\mathbf{1}$ and $\mathbf{2}$.

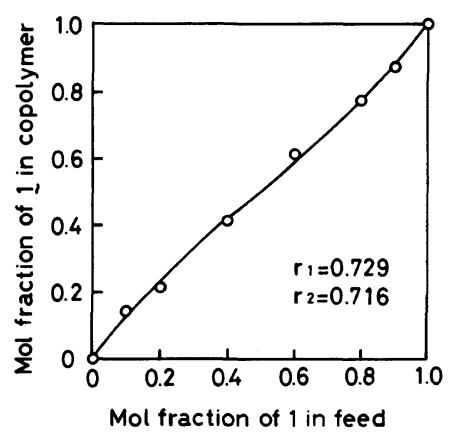

Figure 5. Copolymer composition curve of the copolymerization of $\mathbf{1}$ and $\mathbf{2}$.

the direct polycondensation to form polyamide under mild conditions. System (2) which was a combination of Poly-1 or Poly(1co-2) and $\mathrm{C}_{2} \mathrm{Cl}_{6}$ was superior to system (1) which was a combination of Poly-1 oxide and $(\mathrm{COCl})_{2}$, when solution viscosities of the re- 
Direct Polycondensation

Table II. Direct polycondensation using polymeric TPP for the synthesis of polyamides

\begin{tabular}{|c|c|c|c|c|c|c|c|}
\hline \multicolumn{2}{|c|}{ Initiator } & \multicolumn{2}{|c|}{ Monomer } & \multirow{3}{*}{ Solvent $^{d}$} & \multirow{3}{*}{$\begin{array}{c}\text { Acid } \\
\text { acceptor }\end{array}$} & \multicolumn{2}{|c|}{ Polymer } \\
\hline \multirow{2}{*}{ System } & \multirow{2}{*}{$\begin{array}{c}\text { Mole } \\
\text { fraction } \\
\text { of TPP }\end{array}$} & \multirow{2}{*}{ Kind } & \multirow{2}{*}{$\frac{\text { Concn. }}{\mathrm{mol} \mathrm{dm}^{-3}}$} & & & Yield & \\
\hline & & & & & & $\%$ & $/ \mathrm{sp} / \mathrm{c}$ \\
\hline \multirow[t]{4}{*}{ (1) } & 1.0 & TPA/APE ${ }^{a}$ & 0.15 & NB & Py & 26 & 0.26 \\
\hline & 1.0 & TPA/APE ${ }^{a}$ & 0.15 & CB & Py & 35 & 0.31 \\
\hline & 1.0 & 4-ABA ${ }^{b}$ & 0.15 & $\mathrm{CB}$ & TEA & 16 & 0.30 \\
\hline & 1.0 & 4-ABA ${ }^{b}$ & 0.15 & NB & Py & $>100$ & 0.38 \\
\hline \multirow[t]{17}{*}{ (2) } & $1^{\mathrm{c}}$ & 4-ABA & 0.400 & Py & Py & 89 & 2.87 \\
\hline & 1.0 & 4-ABA & 0.042 & $\mathrm{Py}$ & Py & $>100$ & 0.37 \\
\hline & 1.0 & 4-ABA & 0.083 & Py & Py & $>100$ & 0.46 \\
\hline & 1.0 & 4-ABA & 0.160 & Py & Py & $>100$ & 0.49 \\
\hline & 1.0 & 4-ABA & 0.167 & Py & Py & $>100$ & 0.51 \\
\hline & 1.0 & 4-ABA & 0.417 & Py & Py & $>100$ & 0.71 \\
\hline & 1.0 & 4-ABA & 0.833 & Py & Py & $>100$ & 0.90 \\
\hline & 1.0 & 4-ABA & 0.250 & NMP & None & $>100$ & 0.61 \\
\hline & 0.877 & 4-ABA & 0.250 & NMP & None & $>100$ & 0.78 \\
\hline & 0.788 & 4-ABA & 0.250 & NMP & None & $>100$ & 0.75 \\
\hline & 0.428 & 4-ABA & 0.250 & NMP & None & 43 & 0.66 \\
\hline & 0.345 & 4-ABA & 0.100 & NMP & None & 47 & 0.25 \\
\hline & 0.343 & 4-ABA & 0.05 & NMP & None & 0 & - \\
\hline & 0.343 & 4-ABA & 0.400 & TMU & None & 0 & - \\
\hline & 0.154 & 4-ABA & 0.100 & NMP & None & Trace & - \\
\hline & 0.154 & 4-ABA & 0.0105 & TMU & None & 0 & - \\
\hline & 0.094 & 4-ABA & 0.0139 & NMP & None & Trace & - \\
\hline
\end{tabular}

a TPA/APE $=$ terephthalic acid/4,4'-diaminodiphenyl ether.

b 4 -ABA = 4-aminobenzoic acid.

c $\mathbf{1}=4-\mathrm{SDP}$.

d $\mathrm{NB}=$ nitrobenzene; $\quad \mathrm{CB}=$ chlorobenzene; $\mathrm{Py}=$ pyridine; $\quad \mathrm{TEA}=$ triethylamine; $\mathrm{NMP}=N$-methylpyrrolidone; TMU = tetramethyl urea.

e Measured at a concentration of $0.1 \mathrm{~g} / 10 \mathrm{~cm}^{3}$ in $\mathrm{H}_{2} \mathrm{SO}_{4}$ at $30 \mathrm{C}$.

sulting polyamide were compared.

When the combination of Poly-1 and $\mathrm{C}_{2} \mathrm{Cl}_{6}$ was used, pyridine was required for the initiation of the direct polycondensation. On the other hand, system (2) using Poly(1-co-2) and $\mathrm{C}_{2} \mathrm{Cl}_{6}$ did not require the addition of pyridine for the direct polycondensation since the pyridine moiety was incorporated into the polymeric TPP. System (2) using Poly(1-co-2) and $\mathrm{C}_{2} \mathrm{Cl}_{6}$ is advantageous from a practical point of view since the direct polycondensation reaction proceeded in aprotic amide solvents such as $N$-methylpyrrolidone (NMP) or tetramethyl urea (TMU) without adding pyridine as an acid acceptor.

The resulting polymers were characterized as corresponding polyamides from infrared and elemental analyses. However, the yields of the polyamides frequently exceeded $100 \%$ and elemental analysis of the resulting polyamide revealed the existence of a small amount of phosphorus atom $(1-3 \%)$. Therefore, the resulting polyamides contained small amounts of the polymeric TPP initiator. The complete separation of the combined initiator was very difficult by a simple extraction with a solvent and a hydrolytic cleavage of the combined initiator might be required.

As seen in Table II, both yields and solution viscosities of the resulting polyamide decreased with decreasing content of TPP in Poly(1-co-2) and a favorable composition of 
Table III. Direct polycondensation using polymeric TPP for the synthesis of polyester

\begin{tabular}{|c|c|c|c|c|c|}
\hline \multirow{3}{*}{ Monomer $^{\mathrm{a}}$} & \multirow{3}{*}{$\begin{array}{l}\text { Initiator } \mathrm{P} / \mathrm{N} \text { ratio } \\
\quad\left(\operatorname{Poly}\left(\mathbf{1}-\mathrm{co}_{-} \mathbf{2}\right)\right)\end{array}$} & \multirow{3}{*}{ Solvent $^{b}$} & \multirow{3}{*}{ Acid acceptor } & \multicolumn{2}{|c|}{ Polymer } \\
\hline & & & & Yield & $n$ \\
\hline & & & & $\%$ & \\
\hline \multirow[t]{3}{*}{ IPA/BPA } & $1.0 / 0$ & Py & Py & 25 & 0.56 \\
\hline & $1.0 / 0$ & $\mathrm{CB}$ & Py & 27 & 0.26 \\
\hline & $0.88 / 0.12$ & Py & Py & 23 & 0.13 \\
\hline \multirow[t]{9}{*}{ TPA/BPA } & $0.79 / 0.21$ & CB & None & 100 & 0.31 \\
\hline & $0.79 / 0.21$ & NB & None & 94 & 0.56 \\
\hline & $0.79 / 0.21$ & TCE & None & 95 & 0.61 \\
\hline & $0.79 / 0.21$ & CB/NMP (1/1) & None & 99 & 0.61 \\
\hline & $0.79 / 0.21$ & CB/DMAc (1/1) & None & 99 & 0.40 \\
\hline & $0.43 / 0.57$ & $\mathrm{CB}$ & None & 65 & 0.32 \\
\hline & $0.43 / 0.57$ & NB & None & 50 & 0.25 \\
\hline & $0.43 / 0.57$ & TCE & None & 45 & 0.26 \\
\hline & $0.43 / 0.57$ & NB & None & 60 & 0.45 \\
\hline \multirow[t]{6}{*}{ 4-HBA } & $1.0 / 0$ & Py & Py & $>100$ & Insol. \\
\hline & $1.0 / 0$ & $\mathrm{Py} / \beta$-Pico $(1 / 1)$ & Py & 16 & Insol. \\
\hline & $1.0 / 0$ & $\beta$-Pico & $\beta$-Pico & 94 & Insol. \\
\hline & $1.0 / 0$ & $\beta$-Pico/TMU (1/1) & $\beta$-Pico & 86 & Insol. \\
\hline & $1.0 / 0$ & NMP & None & 10 & Insol. \\
\hline & $0.43 / 0.57$ & NMP & None & 0 & - \\
\hline
\end{tabular}

${ }^{a}$ IPA/BPA = isophthalic acid/bisphenol A; TPA/BPA = terephthalic acid/bisphenol A; 4-HBA=4-hydroxybenzoic acid.

b $\mathrm{Py}=$ pyridine; $\quad \mathrm{CB}=$ chlorobenzene; $\quad \mathrm{NB}=$ nitrobenzene; $\quad \mathrm{TCE}=$ tetrachloroethane; $\quad \beta$-pico= $\beta$-picoline; TMU $=$ tetramethyl urea; $\mathrm{NMP}=N$-methylpyrrolidone.

c Measured at a concentration of $0.1 \mathrm{~g} / 10 \mathrm{~cm}^{3}$ in phenol/tetrachloroethane $=1 / 1$ at $30^{\circ} \mathrm{C}$.

Poly(1-co-2) was in the range of $0.9-0.8 / 0.1-$ 0.2 of the molar ratio of 4-SDP and 4-VPy in the copolymers. There were no direct relationships between yields and solution viscosities of resulting polymers since the direct polycondensation was not a simple step-wise polycondensation. The decrease in yields and solution viscosities of resulting polymers with decreasing content of TPP might be attributed to less interactions between TPP and pyridine moieties in Poly(1-co-2) owing to an unfavorable conformation of polymer chains to enhance the formation of an active $N$-phosphonium complex.

It was found that Poly(1-co-2) could produce polyamide in a quantitative yield with a solution viscosity of about 0.7 when NMP was used as the solvent.

\section{(2) Synthesis of Polyesters}

Table III summarizes the results of the direct polycondensation for the synthesis of various polyesters. It can be seen in Table II that polyesters were produced in good yield from terephthalic acid (TPA)/bisphenol-A (BPA) or 4-hydroxybenzoic acid (4-HBA) when the initiator of system (2) was applied to these monomers in various solvents.

The resulting polyesters were characterized by infrared and elemental analyses which revealed the corresponding structures. However, a small amount of phosphorus atoms was found in the resulting polyesters. Solid-phase polycondensation of the polyesters at $230^{\circ} \mathrm{C}$ yielded insoluble and infusible polymers which suggest that a cross-linking reaction takes place as soon as they are heated. Therefore, the 
polymeric initiator might be attached to the resulting polyester and the complete separation of the initiator is difficult.

Poly(1-co-2) which was recovered after the direct polycondensation was applied again for the second run after it was isolated and treated with $(\mathrm{COCl})_{2}$ so that the phosphine oxide group was converted to phosphine dichloride which could initiate the polycondensation. Yields and solution viscosities of the resulting polyesters decreased down to about half and the initiator activity of the recovered Poly(1co-2) decreased by regeneration. However, regeneration was much easier than the monomeric initiator and future remodification of regeneration should make it possible to establish a complete recycling of the initiator.

\section{REFERENCES}

1. N. Yamazaki and F. Higashi, J. Polym. Sci., Polym. Chem. Ed., 12, 2149 (1974).

2. G. Wu, H. Tanaka, K. Sanui, and N. Ogata, J. Polym. Sci., Polym. Lett. Ed., 19, 343 (1981).

3. S. Kitayama, K. Sanui, and N. Ogata, J. Polym. Sci., Polym. Chem. Ed., 22, 2705 (1984).

4. H. M. Relles and R. W. Schluenz, J. Am. Chem. Soc., 96, 6469 (1974).

5. R. C. Weast, Ed., "Handbook of Chemistry and Physics," 57th ed, CRC Press Inc. Cleaveland, U.S.A., P.C-192 (1976-1977).

6. T. Kelen and F. Tüdôs, J. Macromol. Sci., Chem., A9, 1 (1975). 